\title{
Conceptualising Performance Enhancement in Extreme Sports: Combining Physiological and Psychological Perspectives
}

\author{
E. Monasterio ${ }^{1,2}$, E. Brymer ${ }^{3}$, I. Stewart ${ }^{4}$ \\ 1 Canterbury District Health Board Regional Forensic Service, Christchurch, New Zealand \\ 2 Psychological Medicine, Christchurch School of Medicine, University of Otago, Christchurch, New Zealand \\ 3 Australian College of Applied Psychology, Brisbane, Australia \\ 4 Institute of Health and Biomedical Innovation, Queensland University of Technology, Queensland, Australia
}

\section{CORRESPONDING AUTHOR:}

Eric Brymer

Australian College of Applied

Psychology

Brisbane, Australia

E-mail: Eric.brymer@acap.edu.au

DOI:

10.32098/mltj.02.2020.16

LEVEL OF EVIDENCE: $2 a$

\begin{abstract}
SUMMARY
Background. Extreme sports, such as BASE jumping and big wave surfing, are emerging as highly popular sporting activities with profoundly different characteristics to traditional sports. To date, research has generally assumed that performance in extreme sports is based on a homogenous understanding of extreme sports and extreme sport participants.

Methods. A narrative examination of the physiological and psychological literature on extreme sports.

Results. The traditional perspective is limited and overlooks important and nuanced differences which are essential for performance enhancement. Athletes are not a homogenous group of individuals and performance environments provide different challenges. A more nuanced assessment of extreme sports reveals that effective performance and survival in extreme sports is centred on the development of the capacity to make fast, accurate decisions under severe physiological and psychological stress, where getting it wrong might result in serious injuries or death. Enhancing performance in extreme sports depends on understanding these issues and designing programs that appreciate the unique relationship between the individual athletes, the task and the performance environment. Like traditional sports, extreme sports necessitate precise attunement to information in the performance environment. Additionally, the extreme sports environment is constantly changing and dangerous.

Conclusions. A one-size-fits-all approach is not appropriate for performance enhancement in extreme sports. Extreme sports are also different to traditional sports. Gradual immersion in the activity will facilitate attunement to information in the performance environment and the realisation of capacities to make effective decisions essential for successful performance.
\end{abstract}

KEY WORDS

Physiology; psychology; extreme sports; BASE jumping; sport-specific.

\section{INTRODUCTION}

Extreme sports, such as BASE jumping, big wave surfing, rope-free climbing, free-diving and waterfall kayaking, are defined as physical activities where death is a potential outcome of a mismanaged mistake or accident (1). Despite this, participation rates across various extreme sports seem to be increasing faster than many traditional sports $(2,3$, 4). For the most part, suppositions about extreme sports performance and its enhancement have been based on interpretations of research conducted in traditional sport- ing contexts $(5,6)$. However, extreme sports differ from traditional sports in many fundamental ways, which have profound implications for understanding performance and performance enhancement: 1) Extreme sports are mostly non-competitive activities resulting in winning or losing $(7)$; 2) Poor performance in extreme sports is potentially dangerous where death of a participant is a real possibility (8); 3) While activities are still evolving and urban extreme sport examples exist, they usually take place in natural environments, rather than the tightly constrained 
performance environments of traditional sports, (9); 4) they are not generally governed by external regulations or rules that define how the 'game' should be played (7); 5) performance criteria are continually evolving and most often centred around creativity and aesthetics rather than traditional quantitative parameters (e.g. distance, time, score) and the appreciation of high-level performance is not restricted by these pre-set quantitative parameters $(10,11$, 5). While there are similarities, any assumption that performance in extreme sports is the same as other outdoor or adventure sports is incorrect. Although both are physical activities undertaken in natural environments, mishaps in adventure sports are unlikely to lead to death, which indicates fundamental differences $(1,12)$. The environmental variables in extreme sports are more extensive and can be dramatic and unstable. Effective performance relies on the profound understanding of these variables and how unpredictable they can be (i.e. big waves, high mountains with unstable snowpack and weather, wind variability in flying). Individuals need to be attuned to information in these environments, have the capacity to respond to rapidly-changing unpredictable conditions (at times by withdrawing from the activity when conditions are too dangerous), and have the ability to make split-second decisions while participating to achieve their goals, or simply to survive.

For the most part extreme sport research has focused on understanding the reasons behind the choice to participate $(1,13)$ and using traditional theory-driven arguments, which frequently portrays the participants as thrill-seeking, reckless, self-destructive, and pathological daredevils. This perspective often attributes some deficiency to the participant and emphasizes an unhealthy desire for risk and risk-taking as the main driver for participation (1). This approach does not reflect the experience of participants and assumes that the main determinant of performance is the innate ability to handle risks (15). Recent research on extreme sports has revealed that motivations are broader, more positive and life-enhancing, and suggests that effective performance is determined by more than the innate ability to handle serious risk $(8,13,16,17)$. However, knowledge about these functions is still limited. This paper outlines a conceptual framework for understanding effective performance in extreme sports.

\section{Performance enhancement in extreme sports}

Enhancing performance in extreme sports presents nuanced challenges which are less apparent in traditional sporting contexts. Performance enhancement research in traditional sports has resulted in the appreciation that each sport has distinct characteristics that demand sport-specific knowl- edge to facilitate performance enhancement. Additionally, research has proven that each type of sport has subtly different needs for performance enhancement across multiple areas such as decision-making, emotional management, muscle preparation, nutrition.

In contrast, extreme sports are, for the most part, still perceived to be a homogenous group of activities (1). Attempts to understand extreme sports have most often focused on differentiating extreme sports from traditional sports on the basis of perceived differences in task, environmental, individual and sociocultural factors. Extreme sports are perceived to be dangerous sports, performed in dynamic, uncertain and even dangerous physical environments, undertaken by high thrill-seekers, people with a pathological need for risk or people who belong to specific sociocultural subgroups (5). The focus on differentiating extreme sports from traditional sports has led to limited research into the performance enhancement aspects of extreme sports.

In this paper, focus is given to why sport-specific training is crucial in extreme sports where death is the most likely outcome of a mismanaged mistake or accident (1). The physiological and psychological demands of each extreme sport are heavily influenced by the activity being performed and the environment in which it takes place. During free diving, for example, considerable pressure is exerted on an athlete's body as he/she descends to depths of up to $100 \mathrm{~m}$, requiring great physical resilience. Physiological requirements for extreme mountaineering (e.g. climbing Mount Everest without oxygen) are much different than those required for BASE jumping. Participation requires that the athlete has a profound knowledge of the specific performance environment and trains for participation in that specific environment. Additionally, the psychological requirements for multi-day activities, such as polar expeditions, are not the same as those required for solo, rope free climbing. As previously explained, performance in extreme sports is not limited by the traditional idea of winning and losing. Instead, the physiological and psychological requirements for effective performance in extreme sports include the capacity to survive in extreme environments as well as to prepare effectively. This paper argues performance enhancement in extreme sports is underpinned by the relationship between individual characteristics, task characteristics and environmental characteristics.

\section{METHODS}

This paper reviews historical and contemporary scientific articles aims to explore the possibility to develop specific systems and methods to enhance performance in extreme sports, combining physiological and psychological perspec- 
tives. This review is a narrative based on critical studies and does not examine any hypotheses. Indeed, due to the sparse and fragmented literature on this subject area, it was not considerate adequate to conduct a systematic review.

\section{Psychological perspectives}

Traditionally, performance enhancement in extreme sports has been examined from epidemiological and psychological perspectives. Epidemiological research has focused on analysing accidents, injuries and causes of death in extreme sports to improve performance-related issues within individual sports $(5,19,20,21,22)$. Epidemiological research has considered task, individual and environmental factors where the emphasis has been on task and environment. Psychological examination of extreme sports participation and performance commonly concentrates on personality. The primary assumption has been that participation and performance are dependent on the need to experience and manage high risks. However, this approach has been criticised because 1) it does not reflect the lived experience (1), 2) research has identified heterogeneous personality types with limited applicability of this finding $(23,24)$ and3) recent research suggests that the risk-taking personality type is more likely to be aligned with the prevalence of accidents and injuries than with improved performance (15). An important ramification of the traditional dominant risk focus is that other, perhaps more important, psychological aspects have been overlooked (25). From a psychological perspective, effective performance relies on the capacity for critical decision-making in situations accompanied by potentially severe consequences for poor performance. This process involves rapid integration of objective information (rapidly changing environmental variables) and subjective experiences (focus, fear, exhaustion). The regular requirement for split second decision-making under pronounced psychological and physiological stress (for example changing a flight course due to wind variability in proximity flying) is crucial in extreme sports performance. One of the fundamental psychological skills required to perform is the ability to manage fear and stress and even flourish despite its prevalence (9). However, this does not mean that participants do not experience fear. Participants report that they experience fear directly related to the knowledge that a mismanaged mistake could mean death. This research highlights that successful participants spend considerable time and energy mastering the activity, understanding the environments where it is practised and recognize their own capabilities to respond in order to minimise the chance of accidents (including not infrequently deciding to walk away) (1). Strategies to maximise effective participation in this context includes training for mishaps (e.g. big wave surfers using rocks to keep them submerged when practising being underwater), adapting the findings of research into the causes of previous accidents into their activity, and becoming experts on the environment relevant to their activity (1). Participants must also be able to focus on and be present in the activity and attuned to information in the immediate environment (25). Siefert et al. (26) found that expert rock climbers can successfully perceive and act on relevant information in the environment. Hetland et al. (27) examined emotional expression while participating in skiing and determined that performance was linked with high-level focus, likely related to the difficulty of the activity. They also noted that performance was often accompanied by experiences of psychological and physical discomfort- a point recognised in research into polar expeditions (28). Effective performance depends on how well the athlete is psychologically prepared for and adapts to extreme environments (29).

Effective participation depends on self-awareness and the capacity to analyse the environment. In using jumping for example, if the analysis does not suggest a safe jump, then participants invariably decide to walk away (7). Negative feelings are not managed like they might be in traditional sports, rather they are integrated and used as information to guide effective decision-making. Self-knowledge and the capacity to act on self-knowledge can differentiate between life and death (30).

As evidenced by current literature, performance is influenced by capacities to a) make decisions that might include walking away if appropriate, b) live with and accept fear as important information, c) be focused or present during the activity, d) perform when physically and psychologically uncomfortable, e) profound self-awareness of personal capacities, f) commitment to psychological and physical skill development and g) profound knowledge of the environment and attunement to information in the environment (1). Extreme sports performance and performance enhancement is achieved by integrating all the above into split-second decision-making in unstable and dangerous situations.

\section{Physiological perspective}

Physical and psychological predisposition, influenced by genetic makeup, is the fundamental building block for athletic success and has been the driving principle behind talent identification programmes worldwide (30). Once identified, sport-specific training hones an athlete's skills (31). Likewise, participation in extreme sports builds upon genetic physical and mental attributes, while employing a progressive training model to maximise success. 
Performing the chosen activity in physiologically demanding conditions is a hallmark of extreme sports. Whether the conditions are excessive heat, high altitude, or lack of oxygen, the environment provides the physiological challenges associated with extreme sports participation.

All humans exhibit a mammalian diving reflex upon submersion in water, that induces bradycardia and peripheral vasoconstriction, to minimise the rate of oxygen utilisation within the body and subsequently delay the urge to breathe (32). However, apnea-trained free divers have exhibited the ability to develop greater lung volumes than untrained humans (33). They also display enlarged spleens which, upon contraction, increase the amount of oxygen carrying red blood cells $(34,35)$ and an enhanced diving reflex, enabling greater depths to be reached or apnea times to be achieved (33). These training-induced responses facilitate an extended timeframe before physiological urges to breath (diaphragm contractions) are triggered. The current world record for breath holding by a free diver is over 24 minutes. As seen, physical and mental training provides free divers with an acute awareness of their physiological signals and the ability to extend apnea time past their innate physiological breaking point. However, this is not the only sport which athletes must train for hypoxic environments.

Whether ascending Mt. Everest (8,848m), BASE jumping (current world record of 7,700m from Mt. Cho Oyo), extreme hang or paragliding over Broad Peak $(8051 \mathrm{~m})$, or ascending 4526 vertical metres in a single flight $(37,38)$, hypoxic environments challenge the physical and mental capability of many different extreme sport participants. Exposure to these extreme altitudes, without proper training, can reduce the oxygen content within the body to dangerously low levels. However, in the same way that divers can train to improve their body's resistance to apnea, controlled exposure to high altitude (greater than $1500 \mathrm{~m}$ ) can be used to induce both acute and chronic acclimation responses for preventing hypobaric hypoxia (36). The body's initial response to high elevation exposure is an increased heart rate to deliver more blood, and consequently sufficient oxygen to active tissue. Long term acclimation, including training at progressively increasing altitudes, produces favourable physiological adaptations to increase oxygen levels. Increases in the concentration of circulating red blood cells and cellular adaptations are designed to improve circulating oxygen levels and oxygen delivery to the active skeletal muscle cells (39).

While oxygen regulation is one challenge of extreme sports, extremes of ambient temperature also present challenges to normal human thermoregulatory capabilities. For example, the Marathon des Sables, a six-day event in the Sahara Desert, and Badwater 135 mile, commencing in California's Death Valley, represent two of many events which chronically stress an athlete's ability to withstand extreme heat. Aside from an immediate increase in sweating, enhanced skin blood flow and hormonal regulation to preserve body water automatically occurs in all humans when elevations in internal body temperature eventuate; athletes undertaking these extreme endurance events will also display significant levels of heat acclimation. Increased sweat output and an earlier onset to improve evaporative heat loss, as well as expansion of plasma volume help maintain total body water and regulate blood pressure; and a reduction in the internal body temperature set-point all contribute to minimising the risk of potentially fatal exertional heat illness $(40,41,42)$.

\section{CONCLUSIONS}

Performance enhancement in extreme sports cannot be based on the assumption that extreme sports are a homogenous group of activities. Instead, research suggests that there are considerable nuances between each specific discipline, which is dependent upon the relationship between the individual, the activity and the environment. Research suggests that, similar to traditional sports, participants can improve their psychological and physiological requirements through sport-specific training to increase their performance. How this is done will depend on the characteristics of the environment and chosen discipline. As demonstrated, the competencies required for free diving vary greatly from in polar expeditions or BASE jumping. Such understanding is crucial to designing an effective training and preparation strategy for the intended activity. Generic training that assumes one-size fits all extreme sports is not appropriate. Rather, it must be specifically suited to each individual and discipline. Designing training systems in an extreme sport will require a focused appreciation of the relationship between specific performance related environmental and task needs, and individual characteristics. The central tenet of performance in extreme sports is the capacity to endure severe extreme physiological and psychological stress in unstable environments and make effective decisions in context. The development of these capacities suggests the development of individual capacities for psychological adaptation to physiological stress and extreme environments.

\section{CONFLICT OF INTERESTS}

The authors declare that they have no conflict of interests (43). 


\section{REFERENCES}

1. Brymer E, Schweitzer R. Phenomenology and the extreme sports experience, NY, Routledge 2017.

2. Wheaton B. Introduction. In Understanding Lifestyle Sports: Consumption, Identity and Difference Belinda Wheaton 2014; 1-28. New York: Routledge.

3. Brymer E, Houge Mackenzie S. Psychology and the Extreme Sport Experience, In F. Feletti (Ed.) Extreme Sports Medicine, Springer 2016; 3-14.

4. Pain MTG, MA Pain. Essay: Risk Taking in sport. The Lancet 2005; 366(1): S33-S34. doi: 10.1016/S0140-6736(05)67838-5.

5. Brymer E, Feletti F. Beyond risk: The importance of adventure in the life of young people. Annals of Leisure Research (in press). https://www.tandfonline.com/doi/ abs/10.1080/11745398.2019.1659837?journalCode $=$ ranz20.

6. Arijs C, Chroni S, Brymer E, Carless D. Leave your ego at the door: A narrative investigation into effective wingsuit flying. Frontiers in Psychology 2017; 8: 1985. https://doi. org/10.3389/fpsyg.2017.01985.

7. Breivik G. Trends in adventure sports in a post-modern society. Sport in Society 2010; 13(2): 260-273.

8. Brymer E, Schweitzer R. Extreme sports are good for your health: a phenomenological understanding of fear and anxiety in extreme sport. Journal of Health Psychology 2013; 18(4): 477-487. doi: 10.1177/1359105312446770.

9. Brymer E, Downey G, Gray T. Extreme sports as a precursor to environmental sustainability. Journal of Sport and Tourism 2010; 14: 193-204. doi: 10.1080/14775080902965223.

10. Brymer E, Feletti F, Monasterio E, Schweitzer R. Motivation, and impact of extreme sport participation, Frontiers in psychology (in press).

11. Immonen TJ, Brymer E, Davids K, Liukkonen JO, Jaakkola TT. An Ecological Conceptualisation of Extreme Sports. Frontiers in Psychology 2018.

12. Brymer E. Risk and Extreme Sports: A phenomenological perspective, Annals of Leisure Research 2010; 13(1\&2):218-239.

13. Kerr J, Houge Mackenzie S. Multiple motives for participating in adventure sports. Psychology of Sport and Exercise 2012; 13: 649-657.

14. Woodman TM, Barlow CT, Bandura M, Hill D, Kupciw, MacGregor A. Not All Risks are Equal: The Risk Taking Inventory for High-Risk Sports. Journal of Sport and Exercise Psychology 2013; 35(5): 479-492. doi: 10.1123/jsep.35.5.479.

15. Brymer E, Schweitzer RD. Evoking the Ineffable: The phenomenology of extreme sports, Psychology of Consciousness: Theory, Research, and Practice 2017; 4(1):63-74.

16. Brymer E, Schweitzer R. The Search for Freedom in Extreme Sports: A Phenomenological Exploration. Psychology of Sport \& Exercise 2013;14, 6, 865-873.

17. Monasterio E, Cloninger CR. Self-transcendence in mountaineering and BASE Jumping. Frontiers in psychology 2018; 9.

18. Collins L, Brymer E. Understanding nature sports: a participant centred perspective and its implications for the design and facilitating of learning and performance. Annals of Leisure Research.

19. Bouchat P, Brymer E. BASE jumping fatalities between 2007 and 2017: A follow-up of Westman et al.'s descriptive study Wilderness \& Environmental Medicine (in press).
20. Mei-Dan O, Carmont MR, Monasterio E. The epidemiology of severe and catastrophic injuries in BASE jumping. Clinical journal of sport medicine 2012; 22(3): 262-267.

21. Mei-Dan O, Monasterio E, Carmont M, Westman A. Fatalities in wingsuit BASE jumping. Wilderness \& environmental medicine 2013; 24(4): 321-327.

22. Monasterio E. Accident and fatality characteristics in a population of mountain climbers in New Zealand. The New Zealand Medical Journal (Online) 2005;118(1208).

23. Monasterio E, Mei-Dan O, Hackney A. C', Cloninger R. Comparison of the personality traits of male and female BASE jumpers. Frontiers in Psychology 2018; 9:1665.

24. Brymer E, Monasterio E. Exposure \& engagement in mountaineering. In Peter Wolf, Andreas Schweizer, Ludovic Seifert (Eds), Science of Climbing and Mountaineering. Routledge 2016.

25. Monasterio E, Alamri YA, Mei-Dan O. Personality characteristics in a population of mountain climbers. Wilderness \& Environmental Medicine 2014; 25(2):214-219.

26. Seifert L, Orth D, Mantel B, Boulanger J, Hérault R \& Dicks M. Affordance Realization in Climbing: Learning and Transfer. Front. Psychol. 2018; 9:820. doi: 10.3389/fpsyg.2018.00820.

27. Hetland A, Vittersø J, Wie SOB, Kjelstrup E, Mittner M and Dahl TI. Skiing and Thinking About It: Moment-to-Moment and Retrospective Analysis of Emotions in an Extreme Sport. Front. Psychol. 2018; 9:971. doi: 10.3389/fpsyg.2018.00971.

28. Smith N, Barrett EC. Psychology, extreme environments, and counter-terrorism operations, Behavioral Sciences of Terrorism and Political Aggression 2019; 11:1:48-72. Doi: 10.1080/19434472.2018.1551916.

29. Leon G, Sandal G, Larsen E. Human performance in polar environments. Journal of Environmental Psychology 2011. 31. 353-360. 10.1016/j.jenvp.2011.08.001.

30. Vaeyens R, Lenoir M, Williams AM, Philippaerts RM. Talent Identification and Development Programmes in Sport. Sports Medicine 2008;38: 703-714.

31. Baker J, Cote J, Abernethy B. Sport-Specific Practice and the Development of Expert Decision-Making in Team Ball Sports, Journal of Applied Sport Psychology 2003; 15:1: 12-25, Doi: 10.1080/10413200305400.

32. Foster GE, Sheel AW. The human diving response, its function, and its control. Scand J Med Sci Sports 2005; 15: 3-12.

33. Stewart I, Bulmer A, Sharman J, Ridgway L. Arterial Oxygen Desaturation Kinetics during Apnea. Med Sci Sports Exerc. 2005; 37(11): 1871-1876.

34. Schagatay E. Size Matters: Spleen and Lung Volumes Predict Performance in Human Apneic Divers 2012; 3(173). doi:10.3389/fphys.2012.00173.

35. Stewart I, McKenzie D. The human spleen during physiological stress. Sports Med 2002;32(6): 361-369.

36. Tipton MJ, Harper A, Paton JFR, and Costello JT. The human ventilator response to stress: Rate or depth? J Physiol. 2017; 595:5729-5752.

37. Ewing E. 60 Years of Everest: Paragliding and hang gliding on the world's highest peak. Cross Country 2013.

38. Ewing E. Broad Peak 8,051 m. Cross Country 2016; 66-73.

39. Rasmussen P, Siebenmann C, Diaz V, Lundby C. Red Cell Volume Expansion at Altitude: A Meta-analysis and Monte Carlo Simulation. Medicine and science in sports and exercise 2013; 45(9): 1767-1772. 
40. Kenney WL, DeGroot DW, Holowatz LA. Extremes of human heat tolerance: life at the precipice of thermoregulatory failure. Journal of Thermal Biology 2004; 29: 479-485.

41. Périard J, Travers G, Racinais S, Sawka M. Cardiovascular adaptations supporting human exercise-heat acclimation. Autonomic Neuroscience: Basic and Clinical 2016; 196: 52-62.
42. Hein Daanen AM, Wouter D, Van Marken Lichtenbelt. Human whole body cold adaptation, Temperature 2016; 3:1: 104-118, DOI: 10.1080/23328940.2015.1135688.

43. Padulo J, Oliva F, Frizziero A, Maffulli N. Muscles, Ligaments and Tendons Journal - Basic principles and recommendations in clinical and field Science Research: 2018 update. MLTJ 2018; 8(3): $305-307$. 